Information Management and Business Review

Vol. 6, No. 3, pp. 146-155, Jun 2014 (ISSN 2220-3796)

\title{
Effect of Perceived Organizational Politics and Core Self Evaluation on Job Satisfaction
}

\author{
Mehwish Javed1 ${ }^{1}$ Muhammad Abrar1* ${ }^{*}$, Inamul Haq ${ }^{2}$, Milha Shabir \\ ${ }^{1}$ National Textile University, Faisalabad, Pakistan \\ ${ }^{2}$ UCP Business School, University of Central Punjab, Lahore, Pakistan \\ *abrarphd@gmail.com
}

\begin{abstract}
Many studies explore the effect of perception of organizational politics on job satisfaction but a very few investigate for the factors that are salient to this relationship. Perceptions of politics have been considered to be a source of stress at workplace which has detrimental consequences on the desired outcomes. Current study aims to explore the effects of perception of organizational politics (POP) and core self-evaluation (CSE) on employee job satisfaction. The present research also examines core self-evaluation as a moderator in the relationship between perception of organizational politics and job satisfaction. With a sample size of 100 respondents drawn from the health sector of $3^{\text {rd }}$ largest city of Pakistan, named Faisalabad, the current study tested the main effects of POP and CSE on job satisfaction by using a self-administered survey having a total of 30 items. For analyzing the data, SPSS was used. As hypothesized, results show that perceived organizational politics had a significant negative relationship with job satisfaction but the results for CSE were not significant. Furthermore, CSE moderated the relationship of POP and job satisfaction, such that the negative relationship between perception of organizational politics and job satisfaction was weaker when core self-evaluation was high.
\end{abstract}

Keywords: Perception of organizational politics, core self-evaluation, job satisfaction

\section{Introduction}

Recent years, has seen an increase in the trend to search for factors that decrease the effect of perceived organizational politics at workplace. Over the last two decades, political behavior has been studied by researchers of politics primarily as the specific influence tactics or using a combination of these tactics (Ferris, Adams, Kolodinsky, Hochwarter \& Ammeter, 2002; Kipnis, Schmidt \& Wilkinson, 1980; Liden \& Mitchell, 1988; Higgins, Judge \& Ferris, 2003). Present study focuses on perceptions of organizational politics and its aftermath at the workplace. In this research article, we explore the effect of perceived organizational politics on job satisfaction level of an employee when core self evaluation acts as a moderator in this relationship. In spite of many empirical and theoretical studies have been conducted (Kipnis et al., 1980; Vigoda, 2001; Vigoda, 2006), there is very little knowledge and understanding about the boundaries of politics, as well as understanding of the nature, interpretation, growth, and consequences of perceptions of organizational politics (Chang, Rosen \& Levy, 2009).This study aims to explore the effect of POP on job satisfaction in a South Asian culture setting of Pakistan as well as the implications of the effect of CSE on this relationship. Our research adds value as most of the scholarly work on organizational politics has been carried out by scholars and researchers based on the samples from United States and exploration of such studies is very rare in the context of developing countries. Previously researchers and practitioners have largely recognized that organizations are considered to be political in its dealing and that organizational politics is a natural phenomenon. Managers and theorists consider the use of political behavior as a necessity in the organization to get their desired works done at the workplace (Buchanan, 2008). Over the last decade, the researchers have explored a number of antecedent and outcomes and a stream of research studies have been carried out in western cultures to assess the perceptions of politics prevailing in the organizations. So, the current study's utilization of the South-Asian work context will be a worthy addition to this area of research.

Research over the last few decades have demonstrated that POP has significant detrimental consequences on job outcomes such as job satisfaction (Ferris, Frink, Galang, Zhou, Kacmar, Howard, 1996; Vigoda \& Kapun, 2005; Vigoda, 2006, Akanbi, Ayobami \& Ofoegbu, 2013). Organizational politics includes the actions of an 
individual that are frequently directed at gaining personal interests, or in another way to avoid the negative consequences within the organizational sphere (Ferris et al., 2002). More specifically, POP induces a psychological pressure on its beholder that starts an energy depletion action or procedure; this means that individual's efforts to meet the demands of the job, tries to cope them with a gain in counter-productive activities and psychological procedures in return that drains out the individual's personal resources (Crawford, Lepine \& Rich, 2010). Considering the deficiency in theoretical developments on how politics perceptions act upon work outcomes, Chang, Rosen \& Levy (2009) suggested that researchers take into consideration the individual differences and contextual factors as moderators in POP and job outcomes relationships. Abbas et al. (2012) also directed the future research workers to take into account contextual and individual differences that can possibly be play a role in POP and outcomes relationship and the use of personality traits as moderators and mediators between the relationship of perceptions of organizational politics and desired outcomes. Responding to the call of Chang et al. (2009) and Abbas et al. (2012), the current study investigates on the core self-evaluation as moderator between the relationship of POP and work outcomes. Judge et al. (1997) defines core self-evaluations as "basic conclusions or bottom-line evaluations that individuals hold about themselves, the world, and others".

\section{Theory and Hypotheses}

Perception of Organizational Politics \& Job Satisfaction: Perceptions of organizational politics are omnipresent and have diverse effects on work outcomes that in return affect efficiency and effectiveness of the organization (Chang et al., 2009). Perceived organizational politics has received a great deal of attention in the field of human resource management and is generally considered to have detrimental effects on its members within the organizational sphere (Chang et al., 2009; Ferris, Russ \& Fandt, 1989). Previous research explores the motives, intentions and the code of conduct relating to employees considering an organization politically harmed (Bodla \& Danish, 2013). According to Ferris, Harrell-Cook, and Dulebohn (2000: 90), Perceived organizational politics "involve an individual's attribution of behaviors of self-serving intent and is defined as an individual's subjective evaluation about the extent to which the work environment is characterized by co-workers and supervisors who demonstrate such self-serving behavior". Perception of organizational politics has three dimensions according to Ferris et al. (1989); these are "general political behavior", "go along to get ahead" and "pay and promotion". Meta analysis carried out by Chang et al. (2009) analyzed perceptions of organizational politics as a hindrance stressor such that these create stress and cast a stress related association to job satisfaction level. Recent meta-analysis showed variability in the consequences of perception of politics on outcomes (Miller et al., 2008). Low level of job satisfaction was found in the situations where there is high POP among the employees (Ferris, Russ \& Fandt., 1989). Negative relationship between perception of politics and job satisfaction levels is also confirmed by other studies (Bodla\& Danish, 2009, Abbas et al., 2012).

Study of effects of POP across different cultures also reveals adverse consequences of POP. In a study by Vigoda (2001) British \& Israeli cultures highlighted varying effects of POP. The differences were attributed to the factor of power distance among both the cultures as British ranked higher on national culture dimensions than Israel (Hofstede, 1983). Similarly Pakistan's ranking on national cultural dimension is high on power distance like British culture (Hofstede, 1983). Of the dimensions of national culture, Pakistan has the high ranking for uncertainty avoidance, suggesting aversion to uncertainty or deficiency of control. Hofstede (2001) proposes that combination the two national cultural dimensions of power distance and uncertainty avoidance manifests as a context where the leaders have ultimate authority and power, and those formal laws, rules, and regulations reinforce the leadership. In such situations, the existence of formal laws, rules and regulations are in the interest of managerial authority without taking into consideration the interests of subordinates and others (Kacmar \& Ferris, 1991). Thus accounting for cultural dimensions and differences this study tries to replicate the findings that perceptions of politics have, across western cultures and find out the harmful effects that POP could have on work outcomes in Pakistan.

Hypothesis 1: There is negative relationship between perception of organizational politics and employees' job satisfaction.

Core Self Evaluations\& Job Satisfaction: Scholars have studied the personality traits that affect an individual's behavior in the workplace (Judge \& Bono, 2003; Brunborg, 2008). Previous research in this 
regard, suggests that self-concept plays an important role in defining an individual's response they experience and rewards they draw from the work (Judge \& Bono, 2003). The core self-evaluation construct as identified by Judge et al. 1997comprises of four fundamental traits. First, self-esteem is considered to be the most basic expression of the CSE construct as it reflects an overall worth an individual places on himself as a person. Second core self-evaluation's construct named generalized self-efficacy represents an individual's belief in his capability to deal, perform and get success. Third construct of CSE is internal locus of control; it predicts an individual's belief that they have control on attributes in their lives. Fourth construct is a broad trait and one of the dimensions of the five factor model, named emotional stability it reflects a person's ability to stay calm, confident, steady and secure (Judge et al., 1997). CSE is a broad concept which incorporates all four personality traits. Research has widely been conducted on these traits separately, despite the high levels of correlation between the four traits, and these traits separately give the similar form of results with outcomes like job satisfaction level, immanent well being and job performance level (Judge \& Bono, 2001). According to Conservation of Resource Theory, a general stress theory suggests that individuals having high core self evaluations give a buffer effect to a hindrance stressor on employee's job satisfaction level (Harris, Harvey \& Kacmar, 2009). Previous research highlights mixed results about self efficacy's moderated role between the relationship of POP and job satisfaction that is, it intensifies the relationship (Bozeman, Perrewe, Hochwarter and Brymer, 2001).

High self-evaluators, have skills that enable quick response towards problem solving, they appreciate challenging environment and jobs that help them to act more efficiently and achieve high performance and high level of satisfaction (Kammeyer-Mueller, Judge \& Scott, 2009). High self evaluators are more active, motivated and effective in setting high goals for themselves and according to those goals they demonstrate a high level of job satisfaction (Judge\& Bono, 2003). Research has shown that these four traits are highly correlated, further they combined to make a single latent construct (e.g., Judge, Bono, Erez \& Locke, 2005; Judge, Locke, Durham \& Kluger, 1998), and CSE maintains a positive relation with job satisfaction (Judge \& Bono, 2001). Previous studies that are carried out to find the relationship among the two constructs of CSE and job satisfaction have shown that these are highly correlated with each other (Judge \& Bono, 2001); highlighting individual's evaluations regarding one's own self are found to be more satisfied with their jobs (Judge, Locke, Durham, \&Kluger, 1998). Judge et al. (1998) propose that CSE depends on the harmony and relationship existence among the individuals, suggests that the results for CSE and job satisfaction may be culture specific. Core self-evaluations influence the outcomes relating to an individual, but environmental elements too impact workplace behavior (Kacmar, Collins, Harris \& Judge, 2009). Judge et al. (1998) hypothesized and found support for a strong association between CSE and job satisfaction.

Hypothesis 2: Core self-evaluation is positively related to job satisfaction of an employee.

Moderating effect of CSE on POP and Job Satisfaction: Self-monitoring is another personality trait that has been shown to be related to perceptions of organizational politics, suggesting that high self evaluators are skillful in political skill and political behaviors (Zhang, Kwan, Zhang\& Wu, 2012). However, one's internal locus of control is also considered to be important in determining an individual's behavior in POP and it gets great attention in perceptions of politics literature. Researchers view the construct of core self-evaluation as a resource, such that individuals high in CSE cope more effectively with stressors, by giving the individuals a high sense of control or by building optimism (a good resource of coping) in individuals having positive appraisal regarding to his job (Kacmar et al., 2009).Research suggest that individuals having high self esteem and internal locus of control have more threshold level for handling stress and in return shows greater levels of job satisfaction, well being and health than individuals having low level of self esteem and external locus of control (Brunborg, 2008).Previous study on CSE suggest that having high self-efficacy allows an individual to bear high job stress and job complexity which in return provides with greater satisfaction at the workplace (Brunborg, 2008).These propositions have been supported by empirical findings that CSE provides a buffering effect to the organizational constraints and social stressors on outcomes (Kacmar et al., 2009). Hence we hypothesize the following,

Hypothesis 3: Core self-evaluation moderates the relationship of POP and job satisfaction such that the relationship becomes weaker when core self-evaluation is high.

Theoretical Framework: Underlying figure 1.1 depicts the conceptual theoretical framework which was studied in the current research. 
Figure 1: Conceptual Model of the study

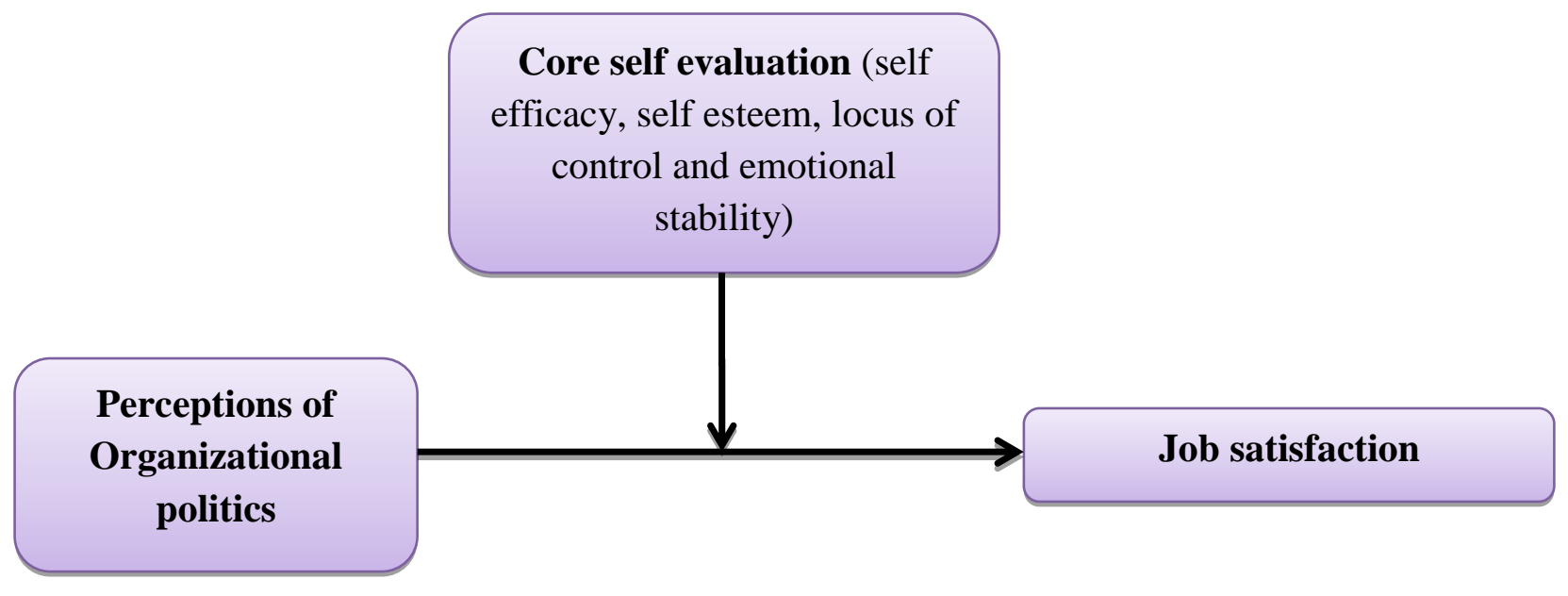

\section{Methodology}

Sample and Data Collection Procedures: Perceptions of organizational politics can deviate substantially across different organizations. Employees perceive it differently and have different effects across different nature of organizations. Previous research in this regard carried out largely on production or manufacturing organizations so for the purpose of capturing full variance among this perception of politics we choose services sector for the collection of data. By using some personal contacts and self-administered surveys we gained access to the doctors and nurses working in private and public hospitals of the third largest city of Pakistan, named Faisalabad. We focused on white collar employees for two reasons. First, organizational politics is more salient to the managers and professional persons than the lower subordinates and labor workers. Second, it is difficult for lower level blue collar employees to respond a questionnaire effectively which is not in their native language. The questionnaire contained a cover letter to inform the respondents about the aim or purpose of the research and assured the respondents about the confidentiality of the answers given by them. In the second step, each respondent provided information on demographical variables such as gender, age, tenure/work experience and organization type in which he/she is currently being working and then provided responses to the items assessing the variables of the study such as POP, CSE and job satisfaction. A total of 150 questionnaires were distributed among the doctors and nurses of hospitals located in Faisalabad out of which 100 self report surveys were received, after completion final response rate was $67 \%$. In our study, majority of respondents were male with a percentage of 57 and the number of female respondents were $43 \%$, having average age of 32 years $(S . D=10.44)$. The average work experience or the tenure on the present position is 6.70 (S.D = 7.93). For analyzing the data and explaining the role of variables, SPSS software was used.

Measures: A self-report questionnaire was used for the purpose of collection of data. All the responses were measured by using a 5 - point Likert-type scale with the anchors $1=$ strongly disagree, $2=$ disagree, $3=$ neither disagree $/$ nor agree, $4=$ agree , and $5=$ strongly agree .

Perceptions of organizational politics (POP): Perceptions of organizational politics were measured by using the 12-item Perceptions of Organizational Politics Scale (POPS) by Kacmar and Ferris (1991). The construct of this scale uses three sub dimensions of perceptions of politics that has 6-items on general political behavior, 4-items capturing, 'go along to get ahead', and 2-items expressing, 'pay and promotion policies'. Examples of items include, for the first dimension "People build themselves up by tearing others down", for the second dimension "In my organization employees are encouraged to speak out" (reverse coded), and for the third dimension "Pay and promotion policies are not politically applied" (reverse coded). Cronbach's alpha reliability for the measure of perception of politics was .72.

Job satisfaction: The job satisfaction of the employee was assessed with Agho, Price and Mueller (1992) scale. This scale consists of six items, examples of the sample items are "I feel fairly well satisfied with my 
present job" and "I am satisfied with my job for the time being". The measure of reliability for job satisfaction was .62.

Core self evaluation: Core- self evaluation was measured using 12-item scale developed by Judge \& Bono, (2003) called Core Self-Evaluation Scale. These 12-items scale address the four components of generalized self-efficacy, self-esteem, emotional stability, and internal locus of control in an integrated and wholistic manner. Example of the items are "When I try, I generally succeed." and "Sometimes I feel depressed" (reverse coded). Cronbach's alpha reliability measure for core self evaluation was .70.

Control Variables: This study used gender, age, and experience and organization type as control variables because of their possible effects on the job outcomes of the current research.

\section{Results}

Table 1 represents the results of descriptive statistics, correlations and estimated reliabilities exist between all the variables. While discussing correlations among the variables it is to be noted that the mean for POP was 3.33, and that for CSE was 3.37. The correlation between the two variables of CSE and POP was -.039. Therefore, a negative relationship has shown among the two variables. The mean for Job satisfaction was 3.54 (S.D = 0.77). The correlation among job satisfaction and POP was -.34 and the result show a negative relationship between POP and Job satisfaction. The correlation result among the variables of CSE and job satisfaction was correlated at 24 it represents a positive relationship among the both variables of CSE and job satisfaction. All the results of correlations are consistent with the previous studies in this field of research.

Table 1: Means, Standard Deviations, Correlations, and Reliabilities

\begin{tabular}{lllllllllll}
\hline & & $\mathbf{M}$ & $\mathbf{S D}$ & $\mathbf{1}$ & $\mathbf{2}$ & $\mathbf{3}$ & $\mathbf{4}$ & $\mathbf{5}$ & $\mathbf{6}$ & $\mathbf{7}$ \\
\hline $\mathbf{1}$ & Age & 32.31 & 10.44 & 1 & & & & & & \\
$\mathbf{2}$ & Gender & 1.43 & 0.498 & $-.384^{* *}$ & 1 & & & & & \\
$\mathbf{3}$ & $\begin{array}{l}\text { Organization } \\
\text { type }\end{array}$ & 1.08 & 0.273 & $.316^{* *}$ & -1.68 & 1 & & & & \\
$\mathbf{4}$ & Experience & 6.7077 & 7.93969 & $.905^{* *}$ & $-.341^{* *}$ & 0.153 & 1 & & & \\
$\mathbf{5}$ & POP & 3.33 & 0.62366 & -0.039 & -1.63 & 0.058 & -0.045 & $\mathbf{( . 7 2 )}$ & & \\
$\mathbf{6}$ & CSE & 3.3775 & 0.51554 & $.289^{* *}$ & -0.154 & $.301^{* *}$ & $.261^{* *}$ & -0.039 & $\mathbf{( . 7 0 )}$ & \\
$\mathbf{7}$ & Job & 3.542 & 0.77605 & 0.097 & -0.013 & -0.028 & 0.129 & $-.347^{* *}$ & $.243^{*}$ & $\mathbf{( . 6 2 )}$ \\
& Satisfaction & & & & & & & & & \\
\hline
\end{tabular}

Note. $N=100$; alpha reliabilities are presented in parentheses. POP = perceived organizational politics; CSE = Core self evaluation.

a. Organizational type: $1=$ public; 2 = private

$* p<.05$.

${ }^{* *} p<.01$.

${ }^{* * *} p<.001$.

Multiple linear regression tests were run to test the hypotheses (Hypothesis 1, 2 and 3). In the first step, all the control variables such as age, gender, organization type and experience were entered followed by all the independent variables. Table 2 shows the results of effects of POP and CSE on job satisfaction. According to the results, perceptions of organizational politics was negatively correlated to job satisfaction $(\beta=-0.33, p<.01)$ supporting hypothesis 1 .

Table 2 shows that CSE was positively related to job satisfaction ( $\beta=0.23$, ns) however this relationship of CSE with Job satisfaction was not significant. So, the results did not provide support to the hypothesis 2 . 
Table 2: Results for Main Effects and Moderated Regression Analyses

\begin{tabular}{lccc}
\hline & \multicolumn{3}{c}{ Job Satisfaction } \\
& $\mathbf{B}$ & $\mathbf{R}^{\mathbf{2}}$ & $\mathbf{\Delta R}^{\mathbf{2}}$ \\
\hline Step 1 & & & \\
Control Variable & & 0.02 & \\
Step 2 & & & \\
POP & $-0.33^{* *}$ & 0.18 & 0.16 \\
CSE & 0.23 & & \\
\hline
\end{tabular}

Note. $N=100 ; \mathrm{POP}=$ perceived organizational politics; CSE = Core self evaluation.

a. Organizational type: $1=$ public; $2=$ private

${ }^{*} p<.05$.

$* * p<.01$.

$* * * p<.001$.

Moderating Influence of CSE: The effect of CSE on POP was examined by using the moderated multiple regression analysis (Cohen, Cohen, West, \& Aiken, 2003) to test the hypothesis 3 . All the control variables in the model were included in the first step, and then the independent variable was entered followed by the moderator variable in the second step. Then in the third step, an interactive item of the independent and the moderator variable was entered, if the interactive variable is significant then the moderation hypothesis is supported.

Table 3: Results for Main Effects and Moderated Regression Analyses

\begin{tabular}{llcc}
\hline & \multicolumn{2}{c}{ Job Satisfaction } \\
& $\mathbf{B}$ & $\mathbf{R}^{\mathbf{2}}$ & $\mathbf{\Delta R}^{\mathbf{2}}$ \\
\hline Step 1 & & & \\
Control Variable & & 0.02 & \\
Step 2 & & & \\
POP & $-0.33^{* *}$ & 0.18 & 0.16 \\
CSE & 0.23 & & \\
Step 3 & & & \\
POP $\times$ CSE & $.25^{*}$ & 0.24 & 0.06 \\
\hline
\end{tabular}

Note. $N=100 ; \mathrm{POP}=$ perceived organizational politics; $\mathrm{CSE}=$ Core self evaluation.

a. Organizational type: $1=$ public; $2=$ private

${ }^{*} p<.05$.

$* * p<.01$.

*** $p<.001$.

Considering step 3 of table 3 it represents the effect of interaction of POP and CSE on the job outcome, this interactive term of POP $\times$ CSE has shown significant results for job satisfaction $(\beta=0.25, p<.05)$. So the result supports the hypothesis 3 .

Discussion: The aim of current research was three fold; one is the exploration of the relationship of perceptions of organizational politics with job satisfaction. Two, understanding the relationship of core selfevaluations with job satisfaction and third is to test the moderating effect of CSE on the relationship of POP and job satisfaction.

Previous researchers generally agreed on the detrimental effects of POP but empirical evidence shows variations in the outcomes across different type of organizations (Chang et al., 2009; Ferris, Russ \& Fandt, 1989; Vigoda, 2002). Based on the results of the present research, our findings clearly support the idea that perceptions of organizational politics decrease the job satisfaction level of an employee. These findings render support to the thought that perceptions of organizational politics are detrimental to the desired work 
outcomes and job satisfaction of an employee. Current research not only focused on exploring the relationship of POP with job satisfaction but also to investigate the moderator and its moderating effect on the relationship of POP and job satisfaction. For this purpose, relationship of CSE with job satisfaction was explored. The result for CSE and Job satisfaction comes out to be non significant which shows that in cultures like Pakistan CSE does not plays its role where there is less harmony and relations are ambiguous at workplace. This is consistent with the observation of Judge et al., 1998 that the results of CSE and job satisfaction may come out in opposite direction in Asian cultures. Finally, the moderating effect of CSE was explored in the relationship of POP and Job satisfaction and the results suggest that an individual's job satisfaction level increases when his/her self concept is high in a situation where POP exists. This result renders support to the concept that an individual's high self-concept helps him in building up his job satisfaction in whatever the situation is. Current findings support the notion that CSE composing of four traits that of self efficacy, locus of control, self esteem and emotional stability serves as threat neutralizer by buffering the negative effects of perceptions of organizational politics on desired outcomes (Kacmar et al., 2009). Considering trait activation theory, a theory relating to an individual's personal traits and situation interaction, core self-evaluations found to be involved in intensifying the diverse and harmful effects of POP on job satisfaction level of an employee (Kacmar et al., 2009).

Previous researchers and psychologists suggests that self-concept resources or the four traits of CSE should be studied in a combined form as these traits do not play or perform in isolation (Judge \& Bono, 2001). Rather, these four traits in combine form provide a better support to each other and play its role in a better way within a mechanism (Judge \& Bono, 2001) that allows the individuals to use the traits effectively and perform well in a stressful environment (Hobfoll, 2002). Current findings propose that past research performed in western cultures can be well generalized to the Pakistani culture. It may be argued that POP by nature is kind of universal. Past researchers have directed future researchers to take into consideration the applying of previous research conducted in western cultures to non-western cultures because most of the research is done in western cultural settings. So, in the current research our focus draws on responding to this call of Abbas et al. (2012) and fits the POP concept on a non western culture like Pakistan. Judge \& Bono, 2003 in his study suggest that Asian culture differs in the sense of harmony and relationship so the results of CSE and job satisfaction differs in the case of Asian cultures. Our findings support the idea that CSE and job satisfaction are not significantly related to each other in an Asian country like Pakistan. Thus, it can be inferred from main findings that POP in a culture like Pakistan acts in the same way as in other cultural settings and has detrimental effects on an individual's satisfaction levels. However, in case of CSE, it does not acts in a certain way that it enhances an individual's satisfaction level at workplace but as a moderator CSE provides a buffering effect to the stressors at workplace that it weakens the relationship of POP and job satisfaction.

Theoretical Contributions: Current findings contribute and enhance the existing line of knowledge on the topic of perception of politics, core self-evaluation and job satisfaction, furthermore it combines the two opposite positive and negative aspects of this field in one research. In the first phase, current findings confirm that POP has detrimental effects on other outcomes as well. Secondly, self-concept plays a crucial role in explaining an employee's satisfaction level as self-concept enhances the positive attitude in an individual so as the satisfaction level. Finally, in the case of moderator we found CSE as a moderator in a situation where POP exist it buffers the adverse impacts of POP and increases an individual's satisfaction in such situation. In addition to these moderating effects CSE plays its role more effectively that individuals with high CSE interpret and look politics differently and act in a positive way in such a situation. They try to perceive some positivity from this environment of negativity. That is why in such cases of organizational politics, CSE can serve as an element because of which individuals can look into a situation and responds to such situations differently.

Practical Implications: Current research renders some valuable and good practical or managerial implications. That if managers and leaders follow they can simply stop their employees to indulge in these kinds of perceptions. Like, manager should first trigger the points and events which are the main reason for POP. They should be aware of detrimental effects of politics at workplace. They should deal with potential contributors of POP that could be ambiguous procedures and policies in an organization, poor communication plans and infrastructures, lack of good governance, guidance and feedback, to reduce the 
effects of POP on employees. Firms that are passing through the procedures of downsizing, restructuring or mergers should be more active and vigilant, as all these procedures creates uncertainty in working environment and therefore increase chances for politics to be arise in the organization.

Strengths and Limitations: The current study has some strengths and unique points in it. First, this is the first research on the moderating role of core self evaluations in the relationship of perceptions of organizational politics and job satisfaction. Second, this is also the first research on this model of POP and CSE and their combined effects on job satisfaction in the cultural context of Pakistan. Third, it is the first study that studies the relationship of POP and core self-evaluations. There are also some limitations of the current study which includes; first limitation of the study is common method biasness. Nevertheless, findings and the results of the POP and its effects on job satisfaction is consistent with the previous research results with the same outcome. And the significant relationships between the variables proposed that method biasness is not an issue, it shows results against such relations. Second limitation of the study, when the reliability for job satisfaction is considered it shows slightly low value $(\alpha=.62)$. However, this result of POP with job satisfaction is consistent with the previous meta analytic results of Miller et al., (2008). Third limitation of the study is we take only one outcome to study the effect of POP on it. However we don't expect that the adverse effects of POP on other outcomes have changed as it is a hindrance stressor at work place.

Future Research Implications: POP in this dynamic era plays its role in every organization. It is the need of almost every organization to know the ways how to get rid of this stressor, so more research is needed in this direction. Future research directions this study carries with itself for the upcoming researchers include; future researchers should be focused on analyzing other personality related factors and cultural contexts as moderators or mediators that can play potentially significant role among perceptions of organizational politics and desired outcomes. For example the use of Big Five Inventory traits as moderator in the relationship of POP with different outcomes may be enhance the understanding that how personal factors can play a crucial and significant role in any situation and can lead to important behavioral and attitudinal aspects in such situations. Future researchers in this domain of research should be focused on effects of POP across different nations, in future a direct comparison of culture to culture or western to non-western culture samples should be used to dig into the moderating effect of cultural aspects. Similarly the researchers may dig out the dimensions of POP in detailed manner and the effect of these dimensions of POP on different work outcomes. Future researchers can also continue their research in exploration of vitality and viability of CSE as higher order construct that enhance the understanding in the field of organizational behavior and human resource management. A person having a positive self concept may prove oneself better towards organizational effectiveness so CSE holds a positive capacity in it. Upcoming researchers should investigate on CSE further with other topics in the field of OB and human resource management.

\section{Conclusion}

Today's global economy is more focused towards Asian regions, as multinationals are more interested in developing their businesses in Asian countries. Unless and until the theories developed in United States and Western cultural contexts has not been applied and tested on the non western cultures, practitioners and researchers would shown trivial or less interest about the generalizability of the research in Asian parts of the world (Tsui et al., 2007). This study gives some understanding \& insights regarding the generalizability of POP and CSE in a country like Pakistan. However, more research attempts and efforts are needed to expand the current knowledge and other complex models are needed to be tested on different cultural aspects and contexts.

\section{References}

Abbas, M., Raja, U., Darr, W. \& Bouckenooghe, D. (2012). Combined effects of perceived politics and psychological capital on job satisfaction, turnover intentions, and performance. Journal of Management, 1(4).

Agho, A. O., Price, J. L. \& Mueller, C. W. (1992). Discriminant validity of measures of job satisfaction, positive affectivity and negative affectivity. Journal of Occupational and Organizational Psychology, 65(3), 185195. 
Akanbi, L., Ayobami, P. \& Ofoegbu, O. E. (2013). Influence of Perception of Organizational Politics on Job Satisfaction among University Workers in Oyo Town, Nigeria. European Journal of Business and Management, 5(2).

Bodla, M. A. \& Danish, R. Q. (2009). Politics and workplace: an empirical examination of the relationship between perceived organizational politics and work performance. South Asian Journal of Management, 16(1), 44-62.

Bodla, M. A. \& Danish, R. Q. (2013). The Use of Influence Tactics in Politicized Organizations: A Look from Gender Perspective. Information Management \& Business Review, 5(9), 456-462.

Bozeman, D. P., Hochwarier, W. A., Perrewe, P. L. \& Brymer, R. A. (2001). Organizational Politics, Perceived Control, and Work Outcomes: Boundary Conditions on the Effects of Politics1. Journal of Applied Social Psychology, 31(3), 486-503.

Brunborg, G. S. (2008). Core Self-Evaluations: A Predictor Variable for Job Stress. European Psychologist, 13(2), 96-102.

Buchanan, D. (2008). You Stab My Back, I'll Stab Yours: Management Experience and Perceptions of Organization Political Behavior. British Journal of Management, 19(1), 49-64.

Chang, C. H., Rosen, C. C. \& Levy, P. E. (2009). The relationship between perceptions of organizational politics and employee attitudes, strain, and behavior: A meta-analytic examination. Academy of Management Journal, 52, 779-801.

Cohen, J., Cohen, P., West, S. G. \& Aiken, L. S. (2003). Applied multiple regression/correlation analysis for the behavioral sciences (3rd Ed). Hillsdale: Erlbaum.

Crawford, E. R., Lepine, J. A. \& Rich, B. L. (2010). Linking job demands and resources to employee engagement and burnout: A theoretical extension and meta-analytic test. Journal of Applied Psychology, 93, 834848.

Ferris, G. R., Adams, G., Kolodinsky, R. W., Hochwarter, W. A. \& Ammeter, A. P. (2002). Perceptions of organizational politics: Theory and research directions. Research in Multi Level Issues, 1, 179-254.

Ferris, G. R., Frink, D. D., Galang, M. C., Zhou, J., Kacmar, M. \& Howard, J. L. (1996). Perceptions of organizational politics: prediction, stress related implications, and outcomes. Human Relations, 49(2), 233-266.

Ferris, G. R., Harrell-Cook, G. \& Dulebohn, J. (2000). Organizational politics: The nature of the relationship between politics perceptions and political behavior. Research in the Sociology of Organizations, 17, 89-130.

Ferris, G. R., Russ, G. S. \& Fandt, P. M. (1989).Politics in organizations. Impression management in the organization, 143(170), 79-100.

Harris, J. K., Harvey, P. \& Kacmar, M. K. (2009). Do Social Stressors Impact Everyone Equally? An Examination of the Moderating Impact of Core Self-evaluations. Journal of Business and Psychology, 24(2), 153-164

Higgins, C., Judge, T. \& Ferris, G. R. (2003). Influence tactics and work outcomes: A meta-analysis. Journal of Organizational Behavior, 24, 89 -106.

Hobfoll, S. E. (2002). Social and psychological resources and adaptation. Review of general psychology, 6(4), 307.

Hofstede, G. (1983). The cultural relativity of organizational practices and theories. Journal of international business studies, 14(2), 75-89.

Hofstede, G. H. (2001). Culture's consequences: Comparing values, behaviors, institutions and organizations across nations. Sage.

Judge, T. A. (2009). Core Self-Evaluations and Work Success. Association for Psychological Science, 18(1), 5862.

Judge, T. A. \& Bono, J. E. (2001). Relationship of Core Self-Evaluations Traits-Self-Esteem, Generalized SelfEfficacy, Locus of Control, and Emotional Stability with Job Satisfaction and Job Performance: A MetaAnalysis. Journal of Applied Psychology, 86(1), 80-92.

Judge, T. A. \& Bono, J. E. (2003). Core Self-Evaluations: A Review of the Trait and its Role in Job Satisfaction and Job Performance. European Journal of Personality, 17, 5-18.

Judge, T. A., Bono, J. E., Erez, A. \& Locke, E. A. (2005). Core Self-Evaluations and Job and Life Satisfaction: The Role of Self-Concordance and Goal Attainment. Journal of Applied Psychology, 90(2), 257-268.

Judge, T. A., Locke, E. A. \& Durham, C. C. (1997). The dispositional causes of job satisfaction: A core evaluations approach. Research in Organizational Behavior, 19(19), 151-188. 
Judge, T. A., Locke, E. A., Durham, C. C. \& Kluger, A. N. (1998). Dispositional effects on job and life satisfaction: The role of core evaluations. Journal of Applied Psychology, 83(1), 17-34.

Kacmar, K. M. \& Ferris, G. R. (1991). Perceptions of organizational politics scale (POPS): Development and construct validation. Educational and Psychological Measurement, 51(1), 193-205.

Kacmar, K. M., Collins, B. J., Harris, K. J. \& Judge, T. A. (2009). Core Self-Evaluations and Job Performance: The Role of the Perceived Work Environment. Journal of Applied Psychology, 94(6), 1572-1580.

Kammeyer-Mueller, J. D., Judge, T. A. \& Scott, B A. (2009). The Role of Core Self-Evaluations in the Coping Process. Journal of Applied Psychology, 94(1), 177-195.

Kipnis, D., Schmidt, S. M. \& Wilkinson, I. (1980). Intra organizational influence tactics: Exploration of getting one's way. Journal of Applied Psychology, 65, 440 - 452.

Liden, R. C. \& Mitchell, T. R. (1988). Ingratiatory behaviors in organizational settings. Academy of Management Review, 13, 572-587.

Miller, B. K., Rutherford, M. A. \& Kolodinsky, R. W. (2008). Perceptions of organizational politics: A metaanalysis of outcomes. Journal of Business and Psychology, 22(3), 209-222.

Tsui, A. S., Nifadkar, S. S. \& Ou, Y. A. (2007). Cross-national, cross-cultural organizational behavior research: Advances, gaps, and recommendations. Journal of Management, 33, 426-478.

Vigoda, E. (2001). Reactions to organizational politics: A cross-cultural examination in Israel and Britain. Human Relations, 54, 1483-1518.

Vigoda, E. (2002). Stress-related aftermaths to workplace politics: The relationships among politics, job distress, and aggressive behavior in organizations. Journal of Organizational Behavior, 23, 1-21.

Vigoda, E. (2006). Citizens' perceptions of politics and ethics in public administration: A five year national study of their relationship to satisfaction with services, trust in governance, and voice orientations. Journal of Public Administration Research and Theory, 17, 285-305.

Vigoda, E. \& Kapun, D. (2005). Perceptions of politics and performance in public and private organizations: A test of one model across two sectors. Policy \& Politics, 33, 251-276.

Zhang, H., Kwan, K, H., Zhang, X. \& Wu, L, Z. (2012). High Core Self-Evaluators Maintain Creativity: A Motivational Model of Abusive Supervision. Journal of Management, in press. 